\section{Os interferentes endócrinos ambientais precisam receber a atenção dos endocrinologistas brasileiros}

\author{
The environmental endocrine disruptors must receive \\ the attention of Brazilian endocrinologists
}

Tania A. S. Sanchez Bachega ${ }^{1,2}$, leda T. Verreschi ${ }^{1,3}$, Elaine M. Costa Frade $^{1,4}$, Francisco Homero D'Abronzo ${ }^{1,5}$, Marise Lazaretti-Castro ${ }^{1,3}$

$\mathrm{O}$ s compostos denominados "interferentes endócrinos" (IEs) são de especial interesse para nossa especialidade, uma vez que o resultado final de seus mecanismos de ação produzirá efeitos agonista ou antagonista dos hormônios e consequente desencadeamento de síndromes com hiper ou hipoatividade hormonal. $\mathrm{O}$ grupo de IEs é heterogêneo e inclui, além de substâncias encontradas na natureza, como os fitoestrogênios, outros compostos artificiais. Dentre esses se destacam os plastificantes, pesticidas, fungicidas, herbicidas, solventes industriais, partículas derivadas da queima de combustíveis, agentes terapêuticos e metais pesados, além de outros.

Em decorrência do crescimento exponencial da produção de compostos químicos nas últimas décadas, aumenta a probabilidade do aparecimento de substâncias com propriedades de IEs e inúmeros trabalhos têm ressaltado os efeitos da exposição crônica a eles. Embora alguns dos nossos pesquisadores tenham se dedicado ao estudo dos interferentes ambientais, essas informações ainda não haviam alcançado a comunidade de endocrinologistas brasileiros de maneira geral. Foi, portanto, uma grata surpresa ler, no fascículo dos ABE\&M, publicado em fevereiro de 2010, o artigo de Fontenele e cols. (1), que realizou uma ampla revisão sobre os IEs e seus efeitos adversos no sistema endócrino.

Gostaríamos, porém, de ressaltar a discussão realizada nesta revisão sobre a importância do bisfenol A (BPA), um dos IEs que mais tem sido estudado na literatura. O BPA está presente em plásticos, plastificantes, selantes dentários, latas de conservas revestidas internamente com filme de polímero, lentes de óculos, mamadeiras, garrafas de água mineral, encanamentos de água de abastecimento, adesivos, impermeabilizantes de papéis etc. Consequentemente, as preocupações com o BPA aumentam, já que pode ser um contaminante de alimentos e bebidas. Considerando-se que alimentos industrializados frequentemente são embalados com produtos plásticos, estes, durante o período de armazenamento, sofrem hidrólise, liberando as moléculas de BPA. Essa liberação é ainda mais acentuada por processos como o congelamento e o aquecimento do plástico (2).

Fontenele e cols. (1) advertem que a exposição mesmo a baixas doses de BPA pode causar inúmeros efeitos biológicos; além de sua capacidade de mimetizar a atividade de estrógenos endógenos e/ou de interferir na ação do receptor nuclear de estrógeno, também são conhecidos efeitos antitireoidianos, na diferenciação e função do sistema nervoso central e no sistema reprodutor. Gostaríamos de salientar que existem evidências de que a exposição ao BPA resulta em alterações qualitativas e quantitati-
${ }^{1}$ Grupo de Trabalho em Desreguladores Endócrinos, Sociedade Brasileira de Endocrinologia e Metabologia, Regional São Paulo, São Paulo, SP, Brasil

${ }^{2}$ Disciplina de Endocrinologia, Faculdade de Medicina da Universidade de São Paulo (FMUSP), São Paulo, SP, Brasil ${ }^{3}$ Disciplina de Endocrinologia, Departamento de Medicina, Escola Paulista de Medicina, Universidade Federal de São Paulo (Unifesp/ EPM), São Paulo, SP, Brasil ${ }^{4}$ FMUSP, São Paulo, SP, Brasil ${ }^{5}$ Faculdade de Medicina de Jundiaí (FMJ), Jundiaí, SP, Brasil

Correspondência para: Marise Lazaretti-Castro Sociedade Brasileira de Endocrinologia

e Metabologia, Regional São Paulo Av. Angélica, 1757, cj. 103 01227-200 - São Paulo, SP, Brasil marise.lazaretti@imabrasil.com.br

Recebido em 5/Nov/2010 Aceito em 19/Jan/2011 
vas do esperma. Em mulheres, estudos epidemiológicos evidenciaram correlação positiva entre a concentração de BPA no sangue e a de andrógenos circulantes em portadoras da síndrome de ovários policísticos (3). As doenças associadas ao BPA não se limitam às áreas endocrinológica e oncológica, pois nesta lista são adicionadas as doenças do sistema imunológico, como o lúpus eritematoso sistêmico, a púrpura trombocitopênica idiopática, a dermatomiosite e a esclerodermia (4).

Um importante aspecto discutido na revisão de Fontenele e cols. (1) foi o do período de exposição aos IEs. O ser humano está sujeito à ação dos IEs durante toda a vida, mas o período de exposição será o principal fator determinante de seus efeitos. Existem períodos com maior suscetibilidade e são denominados de “janelas de exposição", compreendendo principalmente o período pré-natal, reforçando a tese da programação fetal de doenças na vida adulta. Além disso, a primeira infância é outro período em que os órgãos continuam a sofrer um crescimento e desenvolvimento substancial, ficando a programação dos genes sensíveis à ação de agentes externos, incluindo-se os IEs. Atualmente, a Sociedade Americana de Endocrinologia considera que esse último período também pode fazer parte da programação de doenças na vida adulta (5).

O BPA já foi proibido no Canadá, na França, na Dinamarca e na Costa Rica. Os Estados Unidos, principal país produtor e consumidor de plástico no mundo, estão revendo as regras de utilização das embalagens, principalmente em alimentos. Considerando a importância do BPA na contaminação do meio ambiente, recentemente a Sociedade Brasileira de Endocrinologia e Metabologia (SBEM), Regional de São Paulo, iniciou uma campanha de conscientização da população médica e leiga sobre seu uso. Embora a avaliação do estado de evidência do BPA ainda necessite sincronizar os resultados das pesquisas em animais com os dados epidemiológicos humanos, o Grupo de Trabalho em
Desreguladores Endócrinos da SBEM-SP considera que os dados já disponíveis na literatura são suficientes para indicar os procedimentos de cautela e prevenção. Novas pesquisas, com grande número de casos, ainda são imprescindíveis a fim de podermos responder a essas questões de forma definitiva. Entretanto, queremos enfatizar que, mesmo que alguns dos IEs já tenham sido banidos do mercado, ainda poderão, devido à sua longa biodisponibilidade, causar efeitos nocivos à vida por muitos anos. Pensamos que se torna importante a mobilização dos endocrinologistas, aliados às sociedades médicas e Conselhos de Medicina, para que sejam formuladas propostas de políticas públicas de educação visando a um consumo consciente e, no futuro, até mesmo a redução desses produtos da cadeia alimentar humana.

Acknowledgment: Bachega TASS was supported by grant from CNPq \# 30511/2009-2.

Declaração: os autores declaram não haver conflitos de interesse científico neste estudo.

\section{REFERÊNCIAS}

1. Fontenele EGP, Martins MRA, Quidute ARP, Montenegro Jr RM. Contaminantes ambientais e os interferentes endócrinos. Arq Bras Endocrinol Metab. 2010;54(1):6-16.

2. Welshons WV, Nagel SC, vom Saal FS. Large effects from small exposures. III. Endocrine mechanisms mediating effects of bisphenol $A$ at levels of human exposure. Endocrinology. 2006;147(6):56-69.

3. Takeuchi T, Tsutsumi O, Ikezuki Y, Takai Y, Taketani Y. Positive relationship between androgen and the endocrine disruptor, bisphenol $A$, in normal women and women with ovarian dysfunction. Endocr J. 2004;51(2):165-9.

4. Peeva $E$, Zouali M. Spotlight on the role of hormonal factors in the emergence of autoreactive B-lymphocytes. Immunol Lett. 2005;101(2):123-3.

5. vom Saal FS, Akingbemi BT, Belcher SM, Birnbaum LS, Crain DA, Eriksen $M$, et al. Chapel Hill bisphenol A expert panel consensus statement: integration of mechanisms, effects in animals and potential to impact human health at current levels of exposure. Reprod Toxicol. 2007;24(2):131-8. 